\title{
An Analysis of the APEC News in Washington Post from the Perspective of Engagement System Based on Appraisal Theory
}

\author{
Xiaorui Huang \\ Shanxi Normal University, China
}

\begin{abstract}
This paper uses the engagement system of appraisal theory to analyze the news about APEC summit held in Papua New Guinea from the Washington Post, in which the proportion of dialogue expansion and dialogue contraction of engagement resources is 47 and 53, and the contraction resources are slightly higher than the expansion resources. In order to explain that in news discourse, the author refutes other viewpoints while actively expressing his views on the incidents, and also extracts other viewpoints that have reached the objective and reliable information, thus convincing potential readers.
\end{abstract}

Index Terms - appraisal theory, engagement system, APEC summit, dialogue expansion, and dialogue contraction

\section{INTRODUCTION}

The Asia-Pacific Economic Cooperation (APEC), or APEC, is an important economic cooperation forum in the Asia-Pacific region and the highest level of inter-governmental economic cooperation mechanism in the Asia-Pacific region. From November 12 to 18, 2018, the twenty-sixth informal leadership meeting of the Asia-Pacific Economic Cooperation was held in Port Moresby, the capital of Papua New Guinea (PNG in short). PNG hopes that through this meeting, it can promote its own economic development and establish good trade links with other member states. Regarding this meeting, the Washington Post in the United States published news related to the meeting. This article selected one of them to analyze its language from the engagement system of evaluation theory.

Appraisal theory is a new development of Halliday's systemic functional linguistics by Martin et al. The "system" is the center of this theory, the "appraisal" is the focus, and the language is the means in the system. It can be used to express the attitudes, positions and opinions of language users through the analysis of corpus. The evaluation theory not only expresses the attitude, but also expresses the author's discourse resources and these merits. The author selects various evaluation resources with strong interpersonal functions from the language system, which is to strategically implements attitude expression, expands the verbal interaction space with the audience to enhance the language means of the interpersonal negotiation function, and successfully persuades the audience to accept a certain kind of viewpoint and position to achieve the communicative purpose of discourse.

The paper is divided into three parts excluding chapter I Introduction and chapter-V Conclusion. In chapter II, it makes a general review on Appraisal Theory, and gives a brief introduction to APEC. Chapter III is devoted to giving a detailed description on Appraisal Theory. Chapter IV, as the core part of the whole paper, adopts the qualitative and quantitative analytical approaches to investigate the news in the light of the Engagement System of the Appraisal Theory.

\section{LITERATURE REVIEW}

Appraisal system is based on systemic functional linguistics and expands the lexical level of interpersonal meaning research. As the evaluation theory of the semantic system, through the use of the author or the speaker in the process of communication, the position is determined and the attitude is expressed to achieve the final communicative purpose. At present, many scholars have analyzed news from the perspective of evaluation theory, and studied the communicative purpose of the ropeway. The previous studies on news reports are presented in this part, and the introduction of APEC is done in the last section.

\section{A. Previous Studies on News at Home and Abroad}

In recent years, many Western scholars have made great achievements in the study of news discourse. As a language evaluation method, appraisal theory is widely used in discourse analysis. The greatest achievement achieved by applying this theory is the analysis of news discourse. As early as the 1990s, some members of Australian systemic functional linguists turned their attention to the study of news discourse. They observed that news reporters, correspondents, and commentators, and media workers have different identities, and they also have different types of evaluation resources, narrative styles, and ways of voice intervention. Therefore, researchers began the process of 
applying appraisal theory to news discourse. The earliest application of appraisal theory to studying news discourse began with White's doctoral dissertation. White fully explained the interpersonal types of news discourse, social assessment of news reports and texts, and the attitudes of authors and readers related to these meanings. (White, 1998) Rich Iedema, Susan Feez, and White attempted to study the objectivity and subjectivity of news texts. They discussed the difference between arguing and persuasive news genres, and also analyzed the different types of author voices in news texts. (Rich Iedema, Susan Feez \& White, 1994)

With the increasing maturity of appraisal theory, at home, the trend of applying appraisal theory to studying news texts has continued unabated, and has achieved fruitful results. For example, Dong Shirong, guided by the theory of evaluation, analyzed the intervention resources in the discourse of the US presidential election debate, and explored how the intervention resources in the special discourse of the presidential television debate regulate interpersonal meaning. (Dong Shirong, 2011) Xi Xiaoqing studied the intervention resources in the inauguration speech of the US President and pointed out that the speakers in the text achieve the purpose of persuading the audience through a large number of intervention resources. (Xi Xiaoqing, 2012) A Study on Donald Trump's Twitter Discourse on China from the Perspective of Appraisal Theory was written by Li Fang (Li Fang 2018), which examined languages from the perspective of the system of Attitude, Engagement and Graduation. The paper examined the distribution of appraisal resources in Trump's twitters containing word of China or Chinese from 2011 to 2017. Therefore, there are few researches on domestic APEC conference news discourses based on appraisal theory, mainly focusing on the use of appraisal theory to study presidential campaign speeches or television debates. So, this paper will analyse a piece of news report in Washington Post from the Perspective of Engagement System of Appraisal Theory.

\section{B. A Brief Introduction of APEC}

The Asia-Pacific Economic Cooperation (APEC), or APEC, is an important economic cooperation forum in the Asia-Pacific region and the highest level of inter-governmental economic cooperation mechanism in the Asia-Pacific region.

The first ministerial meeting of the Asia-Pacific Economic Cooperation Conference was held from November 5 to 7 , 1989, marking the establishment of the Asia-Pacific Economic Cooperation. In June 1993, it was renamed the Asia-Pacific Economic Cooperation. In November 1991, China was a sovereign state, and Chinese Taipei and Hong Kong, China, formally joined APEC as regional economies. APEC has 21 members. In October 2001, the APEC meeting was held in Shanghai, China. This is the first time that the APEC meeting has been held in China. In 2014, the APEC meeting came to China again after 13 years. As of September 2014, APEC had 21 full members and three observers. The objectives of the Asia-Pacific Economic Cooperation are to maintain economic growth and development, and to promote economic interdependence among members, and to strengthen an open multilateral trading system, and to remove regional trade and investment barriers, and to protect the common interests of the people of the region.

From November 12 to 18, 2018, the twenty-sixth informal leadership meeting of the Asia-Pacific Economic Cooperation was held in Port Moresby, the capital of Papua New Guinea. Papua New Guinea's "National Daily" and "The Courier Post" reported on October 9th that the Prime Minister of Papua New Guinea, who attended the 2013 APEC Leaders' Summit in Indonesia, announced that Papua was officially allowed to host the 2018 APEC Summit. O'Neill said that APEC members cover nearly half of the world's trade and business volume, and joining the APEC organization has made Papua rich. The 2018 APEC meeting will give PNG a unique historical opportunity to showcase cultural and investment opportunities. O'Neill also expressed confidence in organizing the APEC summit. The leaders of the member states delivered an important speech at the meeting, but did not issue a joint declaration, the first time in 26 years since APEC history. The evaluation of the meeting was that the Ministry of Commerce spokesperson's summit replied that the Chinese Ministry of Foreign Affairs has elaborated on this, and Gao Gang stressed that the just-concluded APEC leaders' informal meeting was in host Papua New Guinea. Thanks to the joint efforts of other members, it was a successful meeting and the parties have achieved important and positive results in many fields. China has always insisted on promoting the final consensus through consultations. However, individual members tried to impose their own priorities on all members and were opposed by many members, especially developing members. Since the self-interest has not yet been reached, the defamation of the Chinese side in the relevant news is indispensable.

The paper selects a related report from the Washington Post and uses the engagement system of appraisal theory to analyze the communicative purpose of the report.

\section{THEORETICAL FRAMEWORK}

This part will introduce the development and the categories of appraisal theory.

\section{A. The Development of Appraisal Theory}

The concern on Appraisal in linguistic field began from the research conducted by Martin on Wright It Right program in 1990s. Over the past decades, linguistics has probed into this phenomenon from different perspectives. Although the terminology to name it varied from person to person, such as evaluation, intensity, hedging, stance, Martin et.el used APPRAISAL.(White 1998; Martin \& White 2005) These words are in great semblance since they virtually depict the same linguistic phenomenon. 
In systemic functional linguistics (hereinafter referred to as SFL), people's deviation from interpersonal textual semantics is usually based on grammatical clause-level interpersonal systems, such as mood and modality, which are the starting points for the development of speech function and exchange structure. Martin documents a complementary perspective founded on evaluative lexis on aspects of interpersonal meaning apart from the grammar of dialogic exchange.(Martin, 2000, p142) Appraisal Theory brings more lexis into this semantic evaluation framework to study, depict and explain how the speakers employ language in the texts to evaluate, make attitude-positioning and conduct negotiations. Its preliminary impetus is from the research in the 80s and 90s for the Wright It Right project of the New South Wales Disadvantaged School about the literacy requirements of the discourses of science, technology, media, history, English literature studies, geography and the visual arts, which were carried out by a group of researchers led by Professor James R. Martin of the University of Sydney, and then together with Peter White, Rick Iedema and Joan Rothery, Caroline Coffin, Susan Feez, Sally Humphreys, Henrike Korner, David McInnes, David Rose, Maree Stenglin and Robert Vee, Martin developed the Appraisal System or Appraisal Theory. Among the various projects under NSW projects, the semantic interpersonal issues are the prime emphasis. Initially, it was restrained on the evaluation of the narratives and the literature comments. (Yang Weiting, 2018)

With the expanding development, the on-going research scope is extending to other texts, mainly in written ones, such as the media texts, technology and historical ones. During the discourse analysis, focus will be not only shift to the evaluative lexis but also comprehend the interpersonal and the social relationship implied within the evaluative lexis. Therefore, Appraisal is the semantics of evaluation, which study the evaluative meaning embedded within the texts.

\section{B. The Categories of the Appraisal Theory}

The linguistic domain of Appraisal, in Martin's analysis, is the semantic resources used to negotiate emotions, judgments, and valuations, alongside resources for amplifying and engaging with these evaluations." (Martin, 2000, p145)

Appraisal, broadly speaking, concerns negotiable attitudes emerging in the text. These evaluative resources are theorized under three interacting domains: Attitude, Engagement and Graduation, concerning with the discourse semantic resources mapping the interpersonal meaning. The system of Appraisal Theory set out in Figure 1. (Manin \& White, 2005, p38)

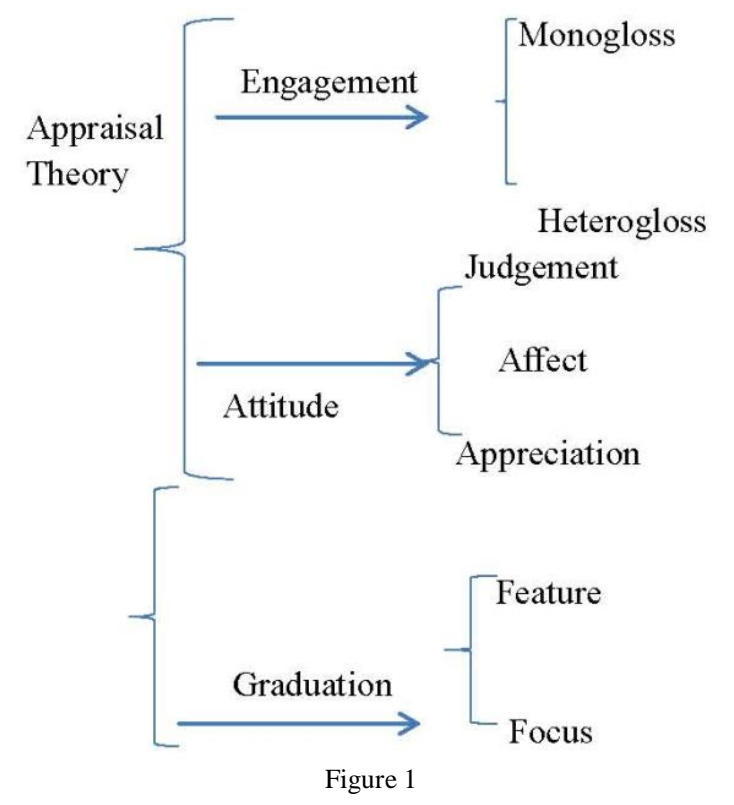

Engagement is the diverse range of resources dealt with the inter-subjective positioning, it provides the means for positioning the speaker's/author's voice with regard to the various propositions and proposals in the text.

Attitude, evaluative use of language, is seen to perform the function of attitudinal positioning. It encompasses three semantic subtype categories: affect (emotion); judgment (ethics); appreciation (aesthetics).

\section{Engagement System}

Martin's definition of engagement can be traced back to Bakhtin's interpretation of language dialogue and later Kristeva's interpretation of textual intertextuality. Bakhtin believed that all discourses were related to each other and to each other, and dialogue was the basic attribute of all discourses.(Bakhtin,1981) Later, Kristeva developed Bakhtin's dialogue theory. She believed that all discourses were composed of quotations, and each discourse was the result of absorbing or transforming other discourses. (Kristeva, 1986) Therefore, any discourse essentially had intertextuality. Martin introduced language dialogue and textual intertextuality into the engagement system, and believed that communicators used language to intervene in resources to negotiate and adjust the dialogue potential between the 
various voices inside and outside the text. The engagement system embodies the game of various viewpoints in and out of the discourse, and how the author establishes alliances with the readers. It is divided into heterogloss and monogloss shown in Figure 2. (Martin, 2005, p104)

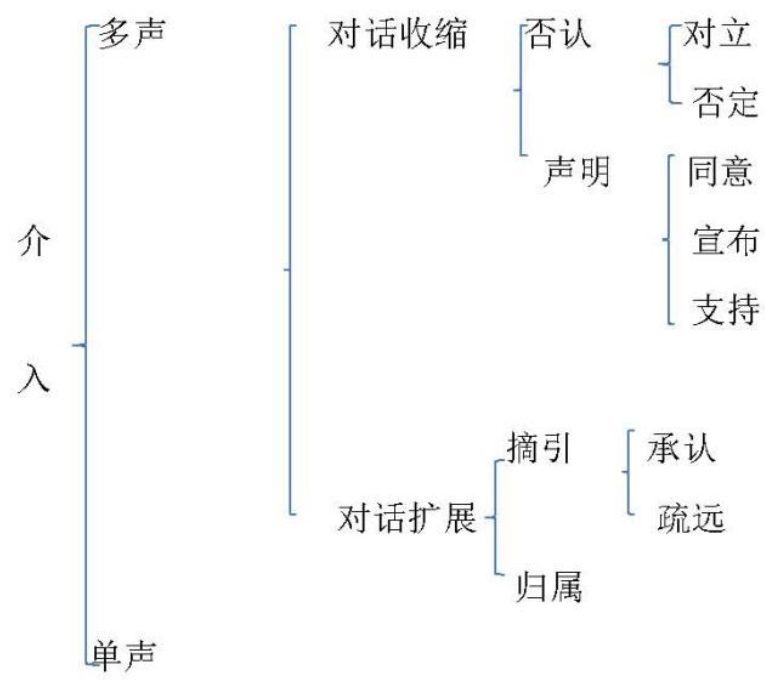

Figure 2

When the discourse creates a dialogue space for multiple sounds or viewpoints, it is heterogloss; a text is monophonic when there is only one voice or opinion. Heterogloss systems contain two main intervention strategies: dialogic contraction and dialogic expansion. The former refers to the restriction of some of the sounds after the introduction of multiple sounds in the text to narrow the dialogue space. The latter refers to the fact that the text introduces a certain voice and actively evokes other voices to expand the dialogue space. Dialogic contractions include disclaims and proclaims. The "denial" strategy directly rejects or refutes a point of view to compress the negotiation space, often through negative words such as "not" or "no" or "turning" words such as "but" and "still". The "declaration" strategy explicitly supports a point of view and indirectly suppresses other positions in order to tighten the space of dialogue. The vocabulary means include "obviously" "no doubt" and "confirmation". Conversation extensions include entries and attributes. The "trigger" strategy implies that a viewpoint (usually the author's point of view) is just one of many viewpoints. It is willing to include other voices in the dialogue space for equal consultation. The common vocabulary means "may", "should" and "I think". The "extraction" strategy clearly indicates that a certain point of view comes from an external voice, is a retelling of other people's words, and is also one of a variety of voices, thereby expanding the space for dialogue and negotiation. The vocabulary means "speak", "claim", "represent", etc.

\section{ANALYSIS AND DISCUSSION}

The corpus selected in this article is a news article published by the Washington Post on the Internet on November 20, 2018, called PORT MORESBY, PAPUA NEW GUINEA. The author is anonymous. This year's news is about the member states of the 2018 APEC Leaders Summit held in Papua New Guinea. This article expresses the US defamation and accusation against China through the use of various interventional resources. The role of the intervention system is to regulate and pass on the responsibility of speaking. For the objectivity and persuasiveness of the article, the author tries to avoid using pure, absolute assertions too high. This paper mainly analyzes the resources from the perspective of intervention. The body length is 1154 words. This discourse contains 28 cases of interventional resources. (As shown in Figure 3).

\begin{tabular}{|c|c|c|c|}
\hline System & Heterogloss & Occurrence Number & Percent \\
\hline \multicolumn{2}{|c|}{ Dialogic Contractions } & 16 & $57 \%$ \\
\hline Engagement & $\begin{array}{l}\text { Dialogic } \\
\text { Expansion }\end{array}$ & 12 & $43 \%$ \\
\hline
\end{tabular}

\section{A. Dialogic Contraction}

There are 16 conversational contractions in this article, accounting for $57 \%$ of the intervention resources. Convergence in dialogue means that the discourse intermediaries challenge, counter or limit other voices and positions, including "disclaim" and "proclaim." "Negation" means that the sound in the text is directly opposite to a certain sound. "Declaration" means that the author has a positive attitude towards the proposition in the discourse, while denying other different voices and suppressing other voices.

(Web Transcription Tool. https://www.washingtonpost.com/news/josh-rogin Accessed 29/11/2018) 
The use of "could not" in Example 1 further embodies the final result of the meeting, which strongly indicates that the failure of the United States to address this joint speech is entirely attributable to China's opposition and secretly condemns China's failure of the summit. Responsibility is all waived to China, and it does not matter to others, causing other countries to believe in the second discussion. The "not" in example 2 shows that the author thinks Chinese official is selfish and private for their own benefits, and the other views that are different from his on Chinese is denied.

The 'agreed to' in Example 3 expresses the author's affirmative attitude, which is a potential support and endorsement. The author agrees the China caused the failure of the joint statement. 'This is especially true' in example 4 also shows the certainty of the conclusion that the behavior of Chinese officials is brazen, and any explanation is refused.

\section{B. Dialogic Expansion}

There were 12 dialogue expansions in the text, accounting for $43 \%$ of the resources involved. "Expansion" means that the intervention in the discourse more or less triggers other voices or positions in the conversation, including entertainment and attribution. The propositions that are triggered are based on connections with other propositions, thus indicating one of many voices. The excerpt is a guide that uses the views of other authors, and is divided into direct and indirect references.

For example 5: Chinese tactics included being thuggish with the international media, busting into government buildings uninvited, papering the capital city of Port Moresby with pro-Beijing propaganda and possibly (entertain) even using cyber attacks to stifle the message of Vice President Pence, the U.S. delegation leader.

For example 6: Second, the paranoid and oversensitive nature of much of China's behavior is a clear indication that the government feels under threat from the United States and its allies. This is something we should (entertain) be aware of (and sensitive to) as we deal with Beijing.

For example 7: When the time ran out and therefore the summit had officially failed, the Chinese delegation stationed in a room near the main session broke out in applause, a U.S. official said (attribute).

For example 8: "This is becoming a bit of a routine in China's official relations: tantrum diplomacy," a senior U.S. official involved in the negotiations told me. (attribute)

(Web Transcription Tool. https://www.washingtonpost.com/news/josh-rogin, accessed 29/11/2018)

In Example 5, the author used possible to illustrate the horror of Chinas strategy, thus convincing the reader that China's strategy was ultimately to not support joint statements, and at the same time, to avoid too subjective evaluations and leave room for other views, the authors only expressed one of a variety of sounds that represent his or his thoughts. In example 6, 'should' shows that one of the views is that China's behavior is hegemonic, and there are many other opinions.

The words 'said' in example 8 and 'told' in example 9 indicate that the author has drawn a clear distance from the point of view. At the same time, the words have left the possibility for other opinions, and also enhanced the objectivity of the article, making the article more convincing. And they persuaded readers to support author's ideas, and built a solid relation with readers.

\section{CONCLUSION}

This paper takes the appraisal system in systemic functional linguistics as the theoretical framework, and analyzes the news selected in the famous American publication "Washington Post", mainly from the perspective of engagement system to explore relationship between the author-reader and the news. The interpersonal orientation and its linguistic means reveal the construction of interpersonal meaning between authors and readers in various engagement resources in news, and explore how journalists can interpret resources to show their posture, build readers, and alienate or close to the reader and establish a relationship with the readers. The appraisal theory is a new vocabulary-grammar framework based on the research process of Halliday's functional grammar interpersonal meaning. The appraisal theory focuses on the various attitudes negotiated in the discourse, the intensity of the emotions involved, and the various ways in which the value and the readers of the union are expressed. Appraisal theory is widely used in discourse analysis, including newspaper discourse. Journalism is dedicated to guiding and disseminating a point of view, convincing the public to agree and support this view. In this paper, due to the limitation of space, the author only discusses and analyzes the application of interventional resources in political news, and the materials analyzed are from the American Press, the Washington Post and the APEC Summit on November 16, 2018. The study found that the intervening resources were regularly distributed in the discourse; even in the subsystem of engagement resources, and the author mainly analyzes it by means of multiple angles. In the analysis of this news, the dialogue shrinks more than the use of dialogue to expand resources. This shows that journalists have retained their own positions and refuted other viewpoints without losing the objectivity of the article. At the same time, they have joined the readers and, in turn, persuaded the readers to win space for dialogue between subjects. The study of intervening resources in political journals provides a new perspective for the construction of interpersonal meanings of authors and readers in discourse. In order to explore the reporter's position in the discourse, he strives for an interpersonal space to express his own views, establish and maintain the relationship between readers with different views, and provide reference for the discourse layout. The evaluation theory, especially the intervention system, has great significance for the development and application of functional linguistics. 
This paper analyzes the resources of political journalism from the perspective of evaluation theory, hoping to provide a new perspective for current research, help political news reporters to improve their insight, grasp the role of intervening resources in the construction of articles, and good understanding of how the author opens the space for interaction and negotiation through the reader-author interpersonal orientation.

\section{REFERENCES}

[1] Dong Shirong. (2011). On the Interpersonal Significance of Involving Resources in the Campaign Debate: Taking the US Presidential Campaign as an Example. Journal of Zhang Zhou Normal University, 3, 82-86.

[2] Iedema, R., Feez, S. \&White, P. R. R. (1994). Media Literacy (Write it Right Literacy in Industry Research Project-Stage2). Sydney: Disadvantaged Schools Program: NSW Department of School Education.

[3] Li Fang. (2018). A Study on Donald Trump's Twitter Discourse on China from the Perspective of Appraisal Theory. Master Thesis, Shanghai International Studies University.

[4] Martin, J. R. (2000). Beyond exchange: appraisal systems in English. In Susan Hunston \& Geoff Thompso (Eds.). Evaluation in Texts: authorial stance and the construction of discourse. Oxford: Oxford University Press, 142 - 145.

[5] Martin J. R. \&White, P. R. (2005). The Language of Evaluation Appraisal in English. Beijing: Foreign Language Teaching and Research Press, 104.

[6] PORT MORESBY, PAPUA NEW GUINEA. (2018). Web Transcription Tool. https://www.washingtonpost.com/news/josh-rogin. (Accessed 29/11/2018)

[7] White, P. R. R. (1998. Telling Media Tales: the News Story as Rhetoric. Sydney: University of Sydney.

[8] Xi Xiaoqing. (2012). A study of intervening resources in in the Discourse of Inaugural Speech. Journal of Xin Jiang University, 40(1), 151-156.

[9] Yang Wenting. (2009). Analysis of Business Review from the perspective of Engagement System of Appraisal Theory. Master Thesis, Southwestern University of Finance and Economics.

Xiaorui Huang was born in Shanxi, China in 1995. She will receive her Master's degree in English linguistics from Shanxi Normal University, in 2021.

She is currently a graduate student in her second year, and majors in Foreign Linguistics and Applied Linguistics in Shanxi Normal University in Lin Fen, China. Her research interests include translation and language teaching practice.

Ms. Huang has published one paper about translation, named An analysis of the Translation Style of New Cyber Words Based on Cultural Translation Theory. 